\title{
VARIATION IN BRANCH FREE LENGTH OF RENAL ARTERY AND ITS CLINICAL SIGNIFICANS: A 64-SLICE CT ANGIOGRAPHIC MOR- PHOMETRIC STUDY
}

\author{
Anshu Mishra *1, P K Sharma 2, Punita Manik ${ }^{3}$. \\ ${ }^{* 1}$ Associate Professor, Department of Anatomy, IIMS \& R, Kursi Road, Lucknow, Uttar Pradesh, \\ India. \\ 2 Professor and Head, Department of Anatomy, ELMC, Lucknow, Uttar Pradesh, India. \\ ${ }^{3}$ Professor, Department of Anatomy, KGMU, Lucknow, Uttar Pradesh, India.

\section{ABSTRACT}

Background: Length of renal artery is an important morphological parameter while performing surgeries in renal area. The present study was conducted to evaluate variations in length of renal artery.

Materials and Methods: The study was conducted in the department of anatomy and department of radiology of King George's Medical University, Lucknow. 53 subjects (106 renal arteries), undergoing 64-slice CT angiography for different indications were included in the study group. The angiographic images of all the subjects in abdominal region were analyzed for renal arteries and their length was measured utilizing computerized tools.

Results: The length of main renal artery varied from $8.5 \mathrm{~mm}$ to $54.8 \mathrm{~mm}$ on the right side. On the left side minimum length was $7.7 \mathrm{~mm}$ and maximum length was $48.8 \mathrm{~mm}$. The average length of renal artery was $30.5 \pm 10.4 \mathrm{~mm}$ on the right side and $26.91 \pm 10.0 \mathrm{~mm}$ on the left side. There was great variation in the length of renal artery due to variation in site of ramification.

Conclusion: The variation of renal artery length is critically important for maintaining vascularity of kidney after surgery.

KEY WORDS: Renal artery, Length, prehilar branching, CT Angiography.

Address for Correspondence: Anshu Mishra, Associate Professor, Department of Anatomy, IIMS \& R, Kursi Road, Lucknow, Uttar Pradesh, India. E-Mail: mishra.anshu685@gmail.com

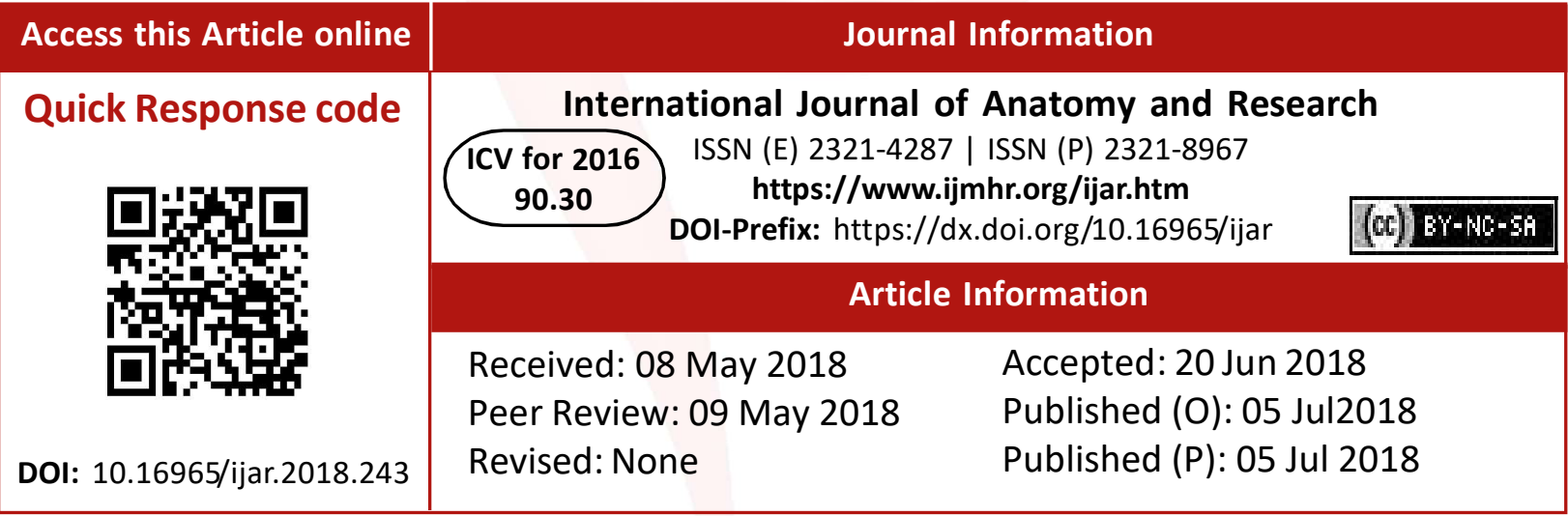

\section{INTRODUCTION}

Renal arteries are paired arteries arising laterally from the aorta at the level of intervertebral disc between L1and L2 vertebra. Near the renal hilum the artery divides into an anterior and a posterior division and these divide in turn into segmental arteries supplying the renal vascular segments [1]. None of the standard textbook mention the normal length of renal artery. As the renal artery shows variation in the site of its division, the length of the vessel is affected accordingly. The length of renal artery from point of its origin from abdominal aorta, to point of its division is important in renal transplant surgeries because a considerable length of renal artery is required for the anastomosis of vascular pedicle of donor kidney in the recipient [2].

Different studies mentioned that the required length of renal artery for successful anastomo- 
sis differently ranged from $1 \mathrm{~cm}$ to $2 \mathrm{~cm}$.

According to Nitin $\mathrm{P}$ Ghonge et al During laproscopic donor nephrectomy, the available operative window needs a minimum arterial pedicle length of $10 \mathrm{~mm}$ [3]. While Kolla Praveen et al mentioned in their study Prehilar (early) branching of the renal artery is a normal variant in which any branch diverge within

$1.5-2.0 \mathrm{~cm}$ from the lateral wall the aorta in the left renal artery or in retrocaval segment of the right renal artery. This variant is important in renal transplantation, because most surgeons usually require at least a $1.5-$ to $2.0-\mathrm{cm}$ length of renal artery before first branching for successful anastamosis [4]. Hence it is important to establish the average normal length of renal artery as well as incidence of short length $(<2 \mathrm{~cm})$ renal arteries.

\section{MATERIALS AND METHODS}

The present study was conducted in the Department of Anatomy and Department of Radiodiagnosis, KGMU, Lucknow. The study group included 53 patients including 33 males and 20 females of age ranging between $13 \mathrm{yrs}$ to $65 y$ rs, with no history or signs of renal diseases. The patients underwent computed tomographic aortic angiographic scan for various indications, at 64-slice CT center of the Department of Radiodiagnosis. After the scan the collected raw data was post processed at computer processing unit and required images were produced in form of volume rendered 3-D images and maximum intensity projection axial images. Computed tomographic angiographic images taken were reviewed for normal anatomy of renal arteries and their variants.

Fig. 1: Volume rendered 3-D image in the region of abdomen visualizing kidneys and renal arteries. Length of renal artery was measured in this by utilizing digital linear tool calibrated on scale seen on left side of image.

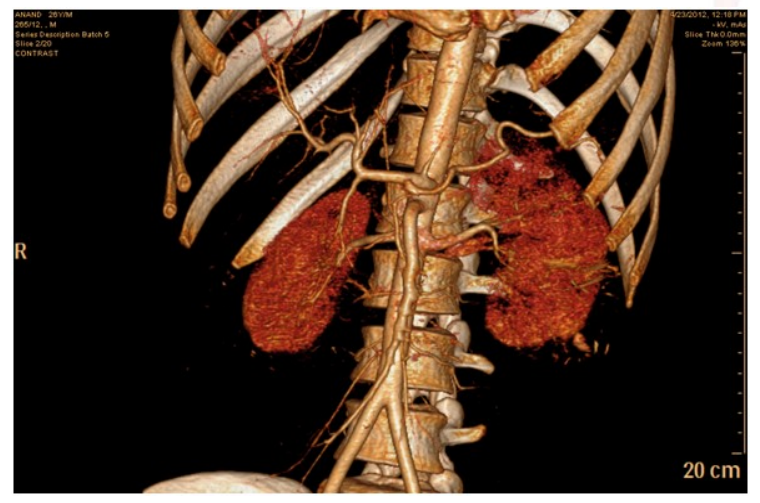

Firstly the renal arteries were identified on both the sides in different images of same subject. In case of more than one renal artery, the vessel with larger diameter was considered as main renal artery. The length of main renal artery was measured form site of origin of artery to appearance of first branch of renal artery both in volume rendered (figure 1 and figure 2) and axial images (figure 3 ) utilizing digital scale.

Fig. 2: Volume rendered 3-D image in the region of abdomen visualizing short length left renal artery dividing prior reaching the hilum.

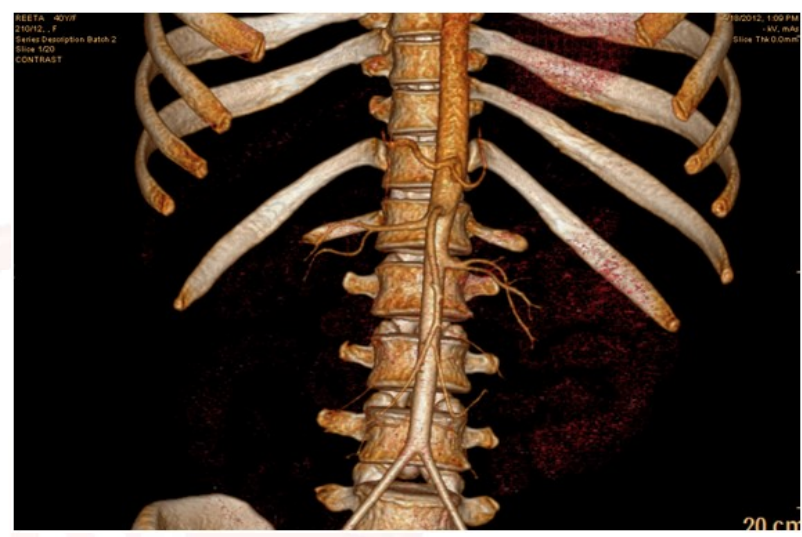

Fig. 3: Axial maximum intensity projection image visualizing right and left kidneys and corresponding renal arteries. Length of left renal artery seen measured with help of digital scale.

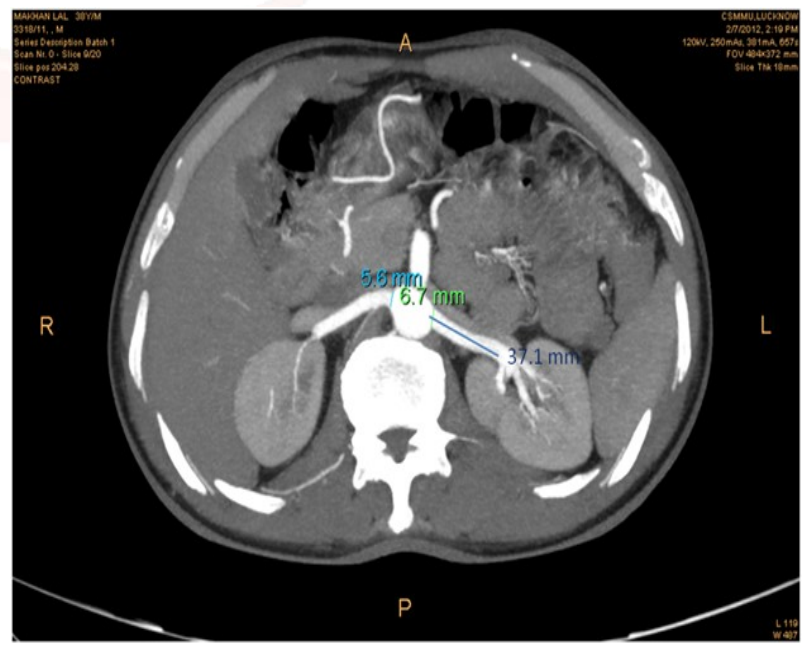

OBSERVATIONS AND RESULTS

In the present study the length of main renal artery varied between $8 \mathrm{~mm}$ to $50 \mathrm{~mm}$. The most common length range observed in the study population was $30-34.9 \mathrm{~mm}$ on the right side in $28.30 \%(\mathrm{~N}=15)$ cases and $35-39.9 \mathrm{~mm}$ on the left side in $20.75 \%$ ( $N=11)$ cases. The observations were grouped in different ranges and are shown in tabular form in table 1. 
The minimum length of main renal artery was $8.5 \mathrm{~mm}$ and maximum length was $54.8 \mathrm{~mm}$ on the right side. On the left side minimum length seen was $7.7 \mathrm{~mm}$ and maximum length was $48.8 \mathrm{~mm}$. The average length of right renal artery observed was $30.5 \pm 10.4 \mathrm{~mm}$ and that of left renal artery was $26.91 \pm 10.0 \mathrm{~mm}$ (table 2). The short-length of renal artery was (early ramification with first $2 \mathrm{~cm}$ ) observed in $15.09 \%$ cases on right side and $22.6 \%$ cases on the left side.

Depending upon the above observation the short length renal vessels were categorized as grade 1 , grade 2 and grade 3 ; mentioned in table 3.

Table 1: Prevalence of different lengths of renal artery on right and left side.

\begin{tabular}{|c|c|c|c|c|}
\hline \multirow{2}{*}{$\begin{array}{c}\text { Length of renal } \\
\text { artery }\end{array}$} & \multicolumn{2}{|c|}{ Right side ( $=53)$} & \multicolumn{2}{c|}{ Left side ( $=53$ ) } \\
\cline { 2 - 5 } & No. & $\%$ & No. & $\%$ \\
\hline$<10.0 \mathrm{~mm}$ & 1 & $1.89 \%$ & 4 & $7.55 \%$ \\
\hline $\mathbf{1 0 . 0 - 1 4 . 9 m m}$ & 4 & $7.55 \%$ & 3 & $5.66 \%$ \\
\hline $\mathbf{1 5 . 0 - 1 9 . 9 m m}$ & 3 & $5.66 \%$ & 5 & $9.43 \%$ \\
\hline $\mathbf{2 0 . 0 - 2 4 . 9 m m}$ & 6 & $11.32 \%$ & 9 & $16.98 \%$ \\
\hline $\mathbf{2 5 . 0 - 2 9 . 9 m m}$ & 10 & $18.87 \%$ & 10 & $18.87 \%$ \\
\hline $\mathbf{3 0 . 0 - 3 4 . 9 m m}$ & 15 & $28.30 \%$ & 8 & $15.09 \%$ \\
\hline $\mathbf{3 5 - 3 9 . 9 m m}$ & 4 & $7.55 \%$ & 11 & $20.75 \%$ \\
\hline $\mathbf{4 0 . 0 - 4 4 . 9 m m}$ & 5 & $9.43 \%$ & 2 & $3.77 \%$ \\
\hline $\mathbf{4 5 . 0 - 4 9 . 9 m m}$ & 3 & $5.66 \%$ & 1 & $1.89 \%$ \\
\hline$>\mathbf{5 0 . 0 m m}$ & 2 & $3.77 \%$ & 0 & $0 \%$ \\
\hline
\end{tabular}

Table 2: Maximum, minimum and average length of right and left renal artery.

\begin{tabular}{|c|c|c|}
\hline & Right renal artery & Left renal artery \\
\hline $\begin{array}{c}\text { Maximum length } \\
\text { (in mm) }\end{array}$ & $54.8 \mathrm{~mm}$ & $48.8 \mathrm{~mm}$ \\
\hline $\begin{array}{c}\text { Minimum length } \\
\text { (in mm) }\end{array}$ & $08.5 \mathrm{~mm}$ & $07.7 \mathrm{~mm}$ \\
\hline Average & $30.5 \pm 10.4 \mathrm{~mm}$ & $26.91 \pm 10.0 \mathrm{~mm}$ \\
\hline
\end{tabular}

Table 3: Incidence of different grades of short length renal arteries.

\begin{tabular}{|c|c|c|c|}
\hline Grade & Length in $\mathrm{mm}$ & $(\mathrm{n}=\mathbf{1 0 6})$ & $\%$ \\
\hline Grade 1 & $15 \mathrm{~mm}-19.9 \mathrm{~mm}$ & 8 & $7.54 \%$ \\
\hline Grade 2 & $10 \mathrm{~mm}-14.9 \mathrm{~mm}$ & 7 & $6.06 \%$ \\
\hline Grade 3 & $<10 \mathrm{~mm}$ & 5 & $4.71 \%$ \\
\hline Total & & 20 & $18.86 \%$ \\
\hline
\end{tabular}

\section{DISCUSSION}

Renal artery variations are common in general population and have gained importance because of the wide spread development in renal transplantation surgery. Recent trend in transplant surgery is to move towards minimally invasive surgeries like laparoscopic procedures to decrease morbidity and mortality.

Accurate evaluation of donors in respect to their renal anatomy and its vasculature is highly important part of donor screening which helps in planning surgery and avoiding complications [5]. Donor screening becomes especially crucial for the laparoscopic harvest of kidney during which operative visibility and surgical exposure are limited, making details of vessel anatomy difficult to appreciate $[5,6]$. Here it is important to note that conversion from laproscopic to the open approach is not infrequent, with vascular injury being the most common reason $[7,8]$.

The length of renal artery from point of origin to point of division is important in renal transplant surgeries because a considerable length of renal artery is required for the anostmosis of vascular pedicle of donor kidney in the recipient. The incidence of short length renal artery varied differently according to different literatures. In a study by Kawamoto et al it was reported that incidence of the short length renal arteries was 19\% [5]. However Saldarriaga et al in 2008 reported incidence of short length renal artery in $8.3 \%$ cases in their study [9]. Other authors also reported presence of short length renal arteries as Holden et al in 12\% cases, Sasaki et al. 10\% cases and Kapoor et al. in $11.8 \%$ cases $[10,11,12]$. In present study the short-length of renal artery was observed in $18.86 \%$ cases, which is comparable to the findings of Kawamoto et al, but higher than reported by other authors.

We had graded the short length renal arteries as grade1, 2 and 3 to further identify the renal arteries having even smaller length reducing the further possibility for the subject to be chosen as donor (table 3 ). We found a considerable incidence of grade 3 small length renal artery which was $4.71 \%$. Findings of present study can be helpful while donor screening for renal transplant surgery.

\section{CONCLUSION}

Length of renal artery showed a great variation and hence it is highly important to consider this parameter while evaluating the donors prior to surgery. The findings of this study will be helpful for interventional radiologist, transplant 
surgeons in planning surgery and avoiding complications.

\section{ACKNOWLEDGEMENTS}

I am thankful to Mr. Aneesh, and Mr. Sanjay for their help in searching relevant data sources and for their effort.

\section{Conflicts of Interests: None}

\section{REFERENCES}

[1]. Standring S, Borley NR, Collins P, Crossman AR, Gatzoulis MA, Healy JC, et al., editors. Gray's Anatomy, The Anatomical basis of clinical practice. $40^{\text {th }}$ ed. New York; Churchill Livingstone; 2008; pp 1231-1232.

[2]. Rydberg J, Kopecky KK, Tann M, Persohn SA, Leapman $S B$, Filo RS, et al. Evaluation of prospective living renal donors for laparoscopic nephrectomy with multisection CT: the marriage of minimally invasive imaging with minimally invasive surgery. Radiographics 2001; 21: 223-236.

[3]. Nitin P Ghonge, Satyabrat Gadanayak1, Vijaya Rajakumari 2 MDCT evaluation of potential living renal donor, prior to laparoscopic donor nephrectomy: What the transplant surgeon wants to know? Indian Journal of Radiology and Imaging 2014; 24 (4): 367 to 378.

[4]. Kolla Praveen1, Pentyala Suneetha2, Lattupalli Hema3, CT angiography of renal arteries: anatomy, variants and its importance in the living donor. IOSR Journal of Dental and Medical Sciences 2016; 15( 8): $73-78$
[5]. Kawamoto S, Montgomery RA, Lawler LP, Horton KM, Fishman EK. Multi-detector row CT evaluation of living renal donors prior to laparoscopic nephrectomy. RadioGraphics 2004; 24: 453-466.

[6]. Zhang J, Hu X, Yin X, Huang T, Ren L, Yin H, et al. The role of multi-detector row $\mathrm{CT}$ in evaluation of living renal donors. Chin J Organ Transplant (Chin) 2009; 30: 419-421.

[7]. Singh AK, Sahani DV, Kagay CR, Kalva SP, Joshi MC, Elias N, et al.; Semiautomated MIP images created directly on 16-section multidetector CT console for evaluation of living renal donors. Radiology, 2007; 244: 583-590.

[8]. Richstone L, Seideman C, Baldinger L, Permpongkosol S, Jarrett TW, Su LM, et al. Conversion during laparoscopic surgery: frequency, indications and risk factors. J Urol 2008; 80: 855-859

[9]. Saldarriaga B, Pinto S A, Ballesteros L B, Morphological expression of the renal artery. A direct anatomical study in a Colombian half-caste population Int. J. Morphol.; 26(1):31-38, 2008.

[10]. Holden A, Smith A, Dukes P et al., Assessment of 100 live potential renal donors for laparoscopic nephrectomy with multidetector row helical CT. Radiol, 2005; 237: 973-80

[11]. Sasaki TM, Finelli F, Burgarin E, Is laparoscopic donor nephrectomy the new criterion standard? Arch. Surg., 2000; 135:943-7.

[12]. Kapoor A, Mahajan G, Singh A, Sarin P; Multispiral CT angiography of renal arteries of live potential renal donors: A review of 118 cases, Transplantation, 2004; 77(10): 1535- 9.

How to cite this article:

Anshu Mishra, P K Sharma, Punita Manik. VARIATION IN BRANCH FREE LENGTH OF RENAL ARTERY AND ITS CLINICAL SIGNIFICANS: A 64-SLICE CT ANGIOGRAPHIC MORPHOMETRIC STUDY. Int J Anat Res 2018;6(3.1):5464-5467. DOI: 10.16965/ijar.2018.243 